\title{
RELEVANSI EPISTEMOLOGI DARI ABID AL-JABIRI TERHADAP PEMBARUAN KURIKULUM PENDIDIKAN AGAMA ISLAM SEKOLAH DASAR
}

\author{
Ridhatullah Assya'bani \\ rassyabani@gmail.com \\ Sekolah Tinggi Ilmu Qur'an (STIQ) Rakha Amuntai
}

\begin{abstract}
Abstrak
Muhammad Abid Al-Jabiri adalah tokoh pemikir kontemporer muslim yang berasal dari Feji, Fekik. AlJabiri adalah tokoh yang pemikirannya sangat berpengaruh pada masa kontemporer. Namanya selalu disebut-sebut dari berbagai kalangan. Ia juga seorang kritikus pada ilmu pengetahuan Arab di Barat dan di Timur. Muhammad Al-Jabiri sangat gigih untuk membangun epistemologi yang bertujuan untuk menyejahterakan perkembangan pada masyarakat, epistemologinya dikenal dengan sebutan irfani, burhani, dan bayani. Epistemologi ini dalam dunia pemikiran, memiliki posisi penting, maka dari itu, AlJabiri mencoba merelevansikan epistemologinya pada pembaruan kurikulum pendidikan Islam Pendidikan Sekolah Dasar. Relevansi pemikiran dari Muhammad Abid Al-Jabiri ini mencoba mengembangkan dengan cara pola sirkular. Pendekatan yang dilakukan adalah dengan pendekatan tematik, yakni pendekatan yang kegiatannya dilakukan dengan cara mengintegrasikan materi pada beberapa mata pelajaran dalam satu topik atau pada satu tema pembahasan sehingga melahirkan melahirkan multidisiplin ilmu. Dengan multidisiplin ilmu, murid-murid atau peserta didik PAI Sekolah Dasar dapat menggunakan intelektualnya dengan cara pandang yang lebih luas. Sehingga melahirkan peserta didik yang pemahamannya ke arah keagamaan yang kontekstual.

Kata Kunci: relevansi epistemologi al-Jabiri, kurikulum pendidikan agama Islam.
\end{abstract}

\section{PENDAHULUAN}

Dalam sejarah Pendidikan Agama Islam (PAI) di Indonesia sendiri, timbul sebagai produk dalam pertarungan perpolitikan ideologi. Dari yang kita ketahui, PAI adalah mata pelajaran yang wajib di Indonesia, harus dibina oleh guru yang beragama Islam tentunya, dan melalui mata pelajaran inilah dapat membuat perpolitikan Islam di Indonesia menjadi maju. Berawal dari tahun 1951 PAI dimasukkan di kurikulum resmi di pemerintahan melalui surat dari menteri pendidikan. Pembelajaran PAI memiliki tugas untuk melestarikan pengetahuanpengetahuan agama Islam, juga dapat menjadi stabilitas politik pada masa itu. Terlebih ketika

Al-Madrasah: Jurnal Ilmiah Pendidikan Madrasah Ibtidaiyah

Vol. 6, No. 1, Januari-Maret 2022 
Ridhatullah Assya'bani : Relevansi Epistemologi dari Abid Al-Jabiri Terhadap Pembaruan Kurikulum Pendidikan Agama Islam Sekolah Dasar

PAI diajarkan pada tingkat pendidikan yang paling rendah, seperti Sekolah Dasar, menjadi penentu pola piker anak untuk selanjutnya.

Pendidikan Agama Islam adalah suatu usaha untuk membina dan mengasuh peserta didik agar senantiasa dapat memahami ajaran Islam secara menyeluruh, menghayati tujuan, dan pada akhirnya dapat mengamalkan serta menjadikan Islam sebagai pandangan hidup. Oleh karena itu, ketika kita menyebut pendidikan Islam, maka akan mencakup dua hal, yaitu: pertama mendidik siswa agar berperilaku sesuai dengan nilai-nilai atau akhlak yang lslami. kedua, mendidik siswasiswi untuk mempelajari materi ajaran Islam (subjek pelajaran berupa pengetahuan tentang ajaran Islam). Dengan ini hamka Hamka Abdul Aziz, membagi tujuan pendidikan berdasarkan pada tujuan pendidikan nasional di atas kedalam dua sasaran; pertama, Sasaran pendidikan hati, yang meliputi; Iman, takwa, akhlak mulia, sehat, mandiri, demokratis, dan tanggung jawab, akan melahirkan manusia baik. Kedua, Sasaran pendidikan otak, meliputi: berilmu, cakap/terampil, dan kreatif, akan melahirkan manusia pintar. ${ }^{1}$

Instansi pendidikan yang ada di Indonesia terbagi menjadi dua, Kementerian pendidikan dan Kementerian Agama. Dari kedua pengelola dan penyelenggara pendidikan formal tersebut, pendidikan formal di bawah binaan kementrian agama memiliki kekhasan hendaknya dapat membawa sekolah menjadi lebih diperhitungkan dalam pembangunan dan pendidikan nasional. Pengetahuan agama menjadi landasan keilmuan Islam di madrasah yang menekankan pada nilai spiritual (iman, aqidah dan untuk membentuk pribadi Islami). Melalui mata pelajaran Pendidikan Agama Islam dianggap dapat menanamkan nilai spiritual dalam diri peserta didik. Jadi pendidikan agama Islam merupakan usaha sadar yang dilakukan pendidik dalam rangka mempersiapkan peserta didik untuk meyakini, memahami, dan mengamalkan ajaran Islam melalui kegiatan bimbingan, pengajaran atau pelatihan yang telah ditentukan untuk mencapai tujuan yang telah ditetapkan.

Isi pelajaran Pendidikan Agama sendiri memuat seperti Al-Qur'an dan hadis, akidah, akhlak, sejarah, dan lain-lain ${ }^{2}$ sehingga PAI dalam memandang sesuatu bisa secara tekstualis seperti nalar bayani. Maka Muhammad Abid Al-Jabiri mencoba mengkaji dan memahami problem tersebut dengan menggunakan epistemologi. Maka dari itu, kajian ini "Relevansi Epistemologi Dari Muhammad Abid Al-Jabiri Dalam Pembaruan Kurikulum Pendidikan Agama Dan Budi Pekerti Sekolah Dasar.

\footnotetext{
${ }^{1}$ Asep A. Aziz dkk., "Pembelajaran Pendidikan Agama Islam (PAI) Di Sekolah Dasar," Taklim : Jurnal Pendidikan Agama Islam 18, no. 2 (21 September 2020): 131-46.

2 Idham Idham, "Problematika Pemanfaatan Buku Pendidikan Agama Islam Pada Sekolah Dasar Di Kabupaten Mamuju," Penamas 28, no. 2 (3 Agustus 2017): 259-76.
}

Al-Madrasah: Jurnal Ilmiah Pendidikan Madrasah Ibtidaiyah Vol. 6, No. 1, Januari-Maret 2022 
Ridhatullah Assya'bani : Relevansi Epistemologi dari Abid Al-Jabiri Terhadap Pembaruan Kurikulum Pendidikan Agama Islam Sekolah Dasar

\section{Biografi Abid Al-Jabiri}

Muhammad Abid Al-Jabiri dikenal orang sebagai tokoh yang yang mengemban semangat Averroisme dan juga ahli pada bidang hermetisme. ${ }^{3}$ Abid Al-Jabiri, nama itu menjadi nama yag sering disebut-sebut sebagai seorang intelektual Islam kontemporer yang berasal dari muslim. Nama lengkap beliau adalah Muhammad Abid Al-Jabiri. Beliau adalah orang yang sangat dihormati dan disegani oleh banyak orang dari berbagai kalangan dan banyak sekali mempengaruhi pemikiran pada generasi selanjutnya. Ia lahir pada tahun 1936 di Feji (Fekik). Ia hidup dengan berkecukupan dan terpandang. Al-Jabiri adalah tokoh yang pemikirannya sangat berpengaruh pada masa kontemporer. Namanya selalu disebut-sebut dari berbagai kalangan. Ia juga seorang kritikus pada ilmu pengetahuan Arab di Barat dan di Timur.

Selagi kecil, dia memang selalu diajarkan pada ilmu agama. Setelahnya berlanjut ke sekolah swasta, lalu pada tahun 1951 sampai tahun 1963 ia lanjut lagi ke sekolah yang bernuansa negeri yakni SMA salah satu di Casablanca. Pada saat Maroko merdeka, saat itulah ia mendapatkan gelar diploma dalam ilmu science. Ia sempat dibimbing oleh Mehdi Ben Barka yang merupakan seorang salah satu pemimpin dari partai Istiqlal. Tidak bisa dipungkiri, bahwa AlJabiri adalah seorang pengagum dari Marxisme, walaupun ia tumbuh di Negara protektoriat Prancis, ia tetap mudah mendapatkan akses buku dan yang berbahasa asing. Untuk mengembangkan ilmunya, sekitar tahun 1958 Al-Jabiri berlanjut menuntut ilmu pada sebuah kampus salah satu di Damaskus Syiria, setelah satu tahun kemudian ia pindah ke Universitas di Rabat yakni Universitas Muhammad Khamis. Al-Jabiri pada saat itu sedang gencar-gencarnya dalam bidang perpolitikan, sehingga pada tahun 1963 ia tertangkap di penjara, akan tetapi pada tahun yang sama ia keluar pada penjara tersebut. Pada masa-masa ia sedang berkuliah di kampus di Rabat, Maroko.

Semenjak saat itu Al-Jabiri sedang dekat-dekatnya dengan tradisi Prancis. Dikarenakan penduduk Prancis di Maroko jumlahnya sangat banyak saat itu, dan dengan alasan ini jugalah yang membuat penduduk Maghrib menjadi dekat dengan tradisi Prancis, dan kebetulan juga secara geografisnya wilayah Maghrib memang lumayan tidak cukup jauh dengan Negara Prancis dibanding pada negara-negara Barat lain-lainnya. Bahasa di Maghrib sekalipun, tidak sedikit penduduknya dalam bahasa sehari-hari menggunakan bahasa Prancis, bisa dibilang selain bahasa Arab dan Berber, bahasa Prancis juga bisa dikatakan bahasa ibu di wilayah Maghrib tersebut.

${ }^{3}$ Ahmad Hasan Ridwan, "Kritik Nalar Arab: Eksposisi Epistemologi Bayani, 'Irfani Dan Burhani Muhammad Abed Al-Jabiri," Afkaruna: Indonesian Interdisciplinary Journal of Islamic Studies 12, no. 2 (27 Desember 2016): 187-222, https://doi.org/10.18196/afkaruna.v12i2.2793.

Al-Madrasah: Jurnal Ilmiah Pendidikan Madrasah Ibtidaiyah Vol. 6, No. 1, Januari-Maret 2022 
Ridhatullah Assya'bani : Relevansi Epistemologi dari Abid Al-Jabiri Terhadap Pembaruan Kurikulum Pendidikan Agama Islam Sekolah Dasar

Bahkan jebolan-jebolan pemikir-pemikir Islam kontemporer banyak alumni yang berasal dari Universitas-Universitas di Prancis.

Di saat ia menikmati menuntut ilmu pada kampus tersebut, Al-Jabiri mulai bersahabat dengan tradisi Prancis, dan pada saait itu juga persfektif dari marxisme mulai sangat berkembang dengan pesatnya, maka dari itu rasa kagumnya itu dengan mengenal marxisme, semakin membuat Al-Jabiri kagumnya makin besar. Contohnya seperti literatur dari Marxisme yang berbahasa asing Abid Al-Jabiri kuasai, akan tetapi setelah ia membaca dan memahami isi dari karya Yves Lacoste tentang Ibn Khaldun, ia mulai meragukan marxisme. Dalam karya tersebut Lacoste berusaha membandingkan antara Ibn Khaldun dan Karl Marx, dan ternyata memang Ibn Khaldunlah yang mendahului Karl Marx mengenai tentang doktrin yang bersangkutan dengan determinasi sosial dan materialism historis. ${ }^{4}$

Ia mendapatkan dan mempunyai gelar doktornya melalui kampusnya, yaitu salah satu kampus yang ada di Rabat, dengan disertasinya yang membahas tentang pemikiran dari Ibn Khaldun, yakni "fanatisme dan Negara: elemen-elemen teoritik khaldunian dalam sejarah Islam". Abid Al-Jabiri juga diposisikan sebagai staf pengajar di fakultas pada universitas tersebut, yakni pada fakultas sastra. Setelah itu pada tahun 1965-1967, Al-Jabiri diposisikan sebagai pengawas pada pendidikan untuk guru-guru yang mengajar filsafat pada tingkat menengah atas. Al-Jabiri pada saat ia menuntut ilmu, ia lebih banyak belajar di tanah kelahirannya sendiri, dari tingkat dasar sampai ia ke tingkat perguruan tinggi. ${ }^{5}$

Beliau ini sebenarnya juga mempunyai pemikirannya mengenai yang lebih dominan ke filsafat. ${ }^{6}$ Intelektual yang dimiliki oleh Al-Jabiri ini memang tak diragukan lagi, namanya bukanlah nama yang asing bagi orang-orang, ia dikenal dengan sebutan "Naqd Al-Aqlal 'Arabi" yakni yang artinya "kritik nalar Arab". Tidak tanggung-tanggung Al-Jabiri membangun kritik nalar terhadap pemikiran Islam ini, kurang lebihnya sekitar 20 tahun lebih, berawal dari tahun 1970-an. Dalam kurun waktu 20 tahun tersebut, ia juga menulis buku, dan yang termasyhur adalah karyanya yang berjudul trilogy "naqd Al-Aql Al-Arabi" yang berjumlah sekitar 1200 halaman lebih. Lalu selanjutnya baru Al-Jabiri menekuni ke bidang perpolitikan Islam yang biasa disebutnya dengan "Al-aql Al-Siyasi Al-Arabi" (nalar politik Arab). Dilihat dari perkembangan

\footnotetext{
${ }^{4}$ Happy Saputra, "Reaktualisasi Tradisi Menuju Transformasi Sosial: Studi Pemikiran Muhammad Abid Al-Jabiri," Substantia: Jurnal Ilmu-Ilmu Ushuluddin 18, no. 1 (11 April 2016): 17-34, https://doi.org/10.22373/substantia.v18i1.3031.

5 M. Faisol, "Struktur Nalar Arab-Islam Menurut Abid al-Jabiri," TSAQAFAH 6, no. 2 (30 November 2010): 335-59, https://doi.org/10.21111/tsaqafah.v6i2.124.

${ }^{6}$ Abdul Mukti Ro'uf, Kritik Nalar Arab Muhammad abid Al-Jabiri (Yogyakarta: LKiS, 2018). 35
}

Al-Madrasah: Jurnal Ilmiah Pendidikan Madrasah Ibtidaiyah

Vol. 6, No. 1, Januari-Maret 2022 
Ridhatullah Assya’bani : Relevansi Epistemologi dari Abid Al-Jabiri Terhadap Pembaruan Kurikulum Pendidikan Agama Islam Sekolah Dasar

pemikir-pemikir di negeri Arab, jelas sosok Al-Jabiri ini tidak hanya menangani problem yang ada di negerinya sendiri lagi, ia juga memulai mengembangkan intelektualnya di negeri Arab setara dengan tokoh-tokoh lain seperti Hasan Hanafi, Muhammad Arkoun, Muhammad Imarah, Fatimah Mernessi, Nasr Hamid Abu Zayd, Bassam Tibi dan lai-lainnya. Karena Al-Jabiri sudah menjadi pemikir kontemporer yang terdepan, ia pun sudah tentu didukung oleh budaya, lingkungan intelektualnya, dan situasi perpolitikan yang ada di dekatnya. Semasa hidupnya AlJabiri, semasa itulah rasionalisme dan demokrasi tidak dihormati, lebihnya sampai dilecehkan. ${ }^{7}$

Dalam buku karangannya yang berjudul "Naqd Al-Aql Al-Arabi", ia menyatakan bahwa apa yang dikatakan oleh teks ataupun sebaliknya itu semua hanya semata untuk merefleksikan ketegangan yang ada antar beberapa nalar-nalar pada masa saat itu. Kemudian hal tersebut sangat penting untuk Al-Jabiri, guna menjadikan teks tersebut sebagai titik tolak bagi kemunculan yang bisa disebut sebagai seperti burhani, irfani dan bayani. ${ }^{8}$

Al-Jabiri pernah meneliti tentang pemikiran Islam dan kebudayaan, akan tetapi Al-Jabiri membatasi diri hanya pada Islam-Arab, dan teksnya yang dilulisnya pun menggunakan bahasa Arab, tidak dengan bahasa asing seperti Persia walaupun padahal ditulis oleh Muslim sendiri. Karyanya yang paling masyhur adalah Naqd Al-aql Arabi, banyak yang mempertanyakan karyanya tersebut, kenapa Al-Jabiri tidak memberi nama dengan sebutan "nalar Islam", mengapa diberi sebutan "nalar Arab'. Di situ Al-Jabiri tidak menjelaskan secara jelas alasannya memberi sebutan dengan nalar Arab, ia hanya menyebutkan bahwa literatur-literatur yang digelutinya berasal dari literatur klasik yang menggunakan bahasa Arab, dan secara geografisnya, kultural, politik dan sosialnya memang berasal dari masyarakat Arab. ${ }^{9}$

Selagi muda Abid Al-Jabiri pernah terlibat pada partai-partai, ia juga pernah aktif menjadi seorang aktifis politik yang berideologi sosial. Selain aktif pada bidang politik, Al-Jabiri juga pernah mnekuni di bidang pendidikan, ia pernah mengajar pelajaran filsafat di sekolah-sekolah pada saat itu. ${ }^{10}$

Seorang Abid Al-Jabiri ini juga bisa dikatakan sebanding dengan tokoh-tokoh intelektuan dari muslim. Contohnya seperti tokoh Hassan Hanafi, Abdullah Ahmad Al-Na'im, Ali Harb, dan

\footnotetext{
${ }^{7}$ Nurliana Damanik, "Muhammad Abid Al-Jabiri," Al-Hikmah: Jurnal Theosofi dan Peradaban Islam 1, no. 2 (11 Juli 2019), https://doi.org/10.51900/alhikmah.v1i2.4843.

${ }^{8}$ Yandi Hafizallah dan Muhammad Abdul Wafa, "Pemikiran Abed Al-Jabiri Terhadap Nalar Arab: Konsep Dan Relevansi," Mawa'izh: Jurnal Dakwah Dan Pengembangan Sosial Kemanusiaan 10, no. 1 (18 Juli 2019): 60-76, https://doi.org/10.32923/maw.v10i1.742.

${ }^{9}$ Nur Lailatul Musyafaah, "Filsafat Epistemologi Islam Muhammad Abid Al Jabiri," AL AFKAR: Jurnal Kajian Keislaman XVII, no. 02 (Desember 2009): 12-21.

${ }^{10}$ Abdul Mukti Ro'uf, Kritik Nalar Arab Muhammad abid Al-Jabiri. 40
}

Al-Madrasah: Jurnal Ilmiah Pendidikan Madrasah Ibtidaiyah

Vol. 6, No. 1, Januari-Maret 2022 
Ridhatullah Assya’bani : Relevansi Epistemologi dari Abid Al-Jabiri Terhadap Pembaruan Kurikulum Pendidikan Agama Islam Sekolah Dasar

Nasr Hamid Abu Zaid. Yang mana pada tokoh-tokoh tersebut merupakan figur-figur cendekiawan dari Muslim yang mempunyai kegigihan dan keberanian yang kuat untuk menjunjung dinamisasi, rasionalisasi, pluralisme, dinamisasi, dan yang terakhir kebebasan. Selain itu Al-Jabiri juga memiliki segudang karyanya yang berjudul, Al-Khitbah Al-Arabi Al-Mu'asir, Nahnu wa AlTurath, Al-Turats wa Al-Hadatsah, Ishkaliyah Al-Fikr Al-Araby Al-Mu'asir, Tahafut Al-Tahafut, Naqd Al-Aql Al-Arabi yang terbagi menjadi 3 yakni Takwin Al-Aql Al-Araby, Al-aql Al-Siyasy Alaraby, dan juga lainnya yang berjudul Dirasah Tahliliyah Naqdiyah. ${ }^{11}$ Berpuluh-puluh karya yang telah dilahirkannya, entah itu yang dibukukannya, maupun tidak. Dan rata-rata yang selalu diangkatnya berbau politik hingga agama. ${ }^{12}$

\section{Relevansi Epistemologi Dari Abid Al-Jabiri Terhadap Pembaruan Kurikulum Pendidikan Agama Islam Sekolah Dasar}

Muhammad Al-Jabiri sangat gigih untuk membangun epistemologi yang bertujuan untuk menyejahterakan perkembangan pada masyarakat. Ia tidak menyetujui dengan gerakan salaf, dan juga menurut Al-Jabiri pembaruan yang terjadi pada saat itu dikendalikan oleh para cendekiawan muslim lain yang mereka bangun menurutnya tidak berkembang dengan baik, dan ia juga tidak menyetujui dengan pemikiran liberal yang menginginkan untuk mengadopsi tradisi Barat dengan cara yang rakus. Hal tersebut terjadi karena dilatar belakangi oleh sejarah Arab dan Barat yang sangat berbeda. Al-Jabiri juga ada mengkritik tentang perihal akal Arab yang gagal untuk melakukan transformasi. Sebagai pemikiran Arab kontemporer Islam, Abid Al-Jabiri juga mencoba untuk memulai terobosan-terobosan alternatif guna untuk melerai permasalahan yang terjadi antara tradisi Islam dan pencapaian-pencapaian modernitas yang diimpikan oleh orang arab. $^{13}$

Pada peradaban kemajuan manusia pada saat ini, ilmu pengetahuan dan juga teknologi menjadi hal yang terpenting pada perkembangan peradaban, bahkan tidak dapat dipungkiri kalau tidak ada sebuah dinamika dan diskursus ilmiah. Pada epistemologi inilah yang dapat melahirkan sebuah ilmu pengetahuan, dan juga epistemologi merupakan salah satu cabang filsafat yang membahas tentang teori pengetahuan. Epistemologi ini dalam dunia pemikiran, memiliki posisi penting, karena yang menentukan kebenaran pengetahuan atau tidaknya ilmu pengtahuan yang

11 Samsul Bahri, "Bayani, Burhani Dan Irfani Trilogi Epistemologi Kegelisahan Seorang Muhammad Abid Al Jabiri," Jurnal Cakrawala Hukum 11, no. 1 (20 April 2017), https://ejournal.up45.ac.id/index.php/cakrawala-hukum/article/view/186.

${ }^{12}$ M. Hasan Ubaidillah, "Konstruksi Nalar Politik Kenegaraan Arab-Islam Perspektif al-Jabiri," AlDaulah: Jurnal Hukum dan Perundangan Islam 2, no. 1 (2012): 68-96.

${ }^{13}$ Musyafaah, "Filsafat Epistemologi Islam Muhammad Abid Al Jabiri."

Al-Madrasah: Jurnal Ilmiah Pendidikan Madrasah Ibtidaiyah

Vol. 6, No. 1, Januari-Maret 2022 
Ridhatullah Assya’bani : Relevansi Epistemologi dari Abid Al-Jabiri Terhadap Pembaruan Kurikulum Pendidikan Agama Islam Sekolah Dasar

dihasilkan, dan juga dapat mnentukan corak pengetahuan. ${ }^{14}$ Tokoh Muhammad Abid Al-Jabiri, seorang tokoh pemikir kontemporer Islam yang mengusung epistemologi Islam dengan mengkrtik nalar Arab, dikarenakan wujud Islam yang tidak dapat dipahami sebagai serakan ide-ide atau pandangan-pandangan yang tidak lurus yang akhirnya mengalami keruntuhan. Akan tetapi lebih membatasi kritiknya, dan lebih fokus kepada kritik epistemologi yang ditujukannnya pada saat itu untuk mekanisme berpikir yang dominan dialami pada peradaban Arab. Dengan epistemologi nalar Arab inilah, Abid Al-jabiri menganggap bahwa epistemologi nalar Arab ini dapat sebagai titik kunci untuk dapat memasuki dunia peradaban Arab yang membentuk secara merata, bahkan sampai seluruh dunia. ${ }^{15}$

Al-Jabiri pernah membaharui kritik nalar Arab pada tradisi keilmuan antara Islam dan arab. Hal itu mempunyai tujuan uatama, yaitu menelusuri ulang budaya yang ada di arab dan Islam dan juga mengkaji tentang nalar arab. Karena Arab adalah tempat yang pertama kali menumbuhkan agama Islam. Pada tugas tersebut, membuat Al-Jabiri juga ingin mengkaji background pada sosio dan politik, keterbukaan nalar Arab-Islam, proses perumusannya, dan juga mengkaji secara mendalam tentang seluk beluknya mekanisme. ${ }^{16}$

Dalam karya Al-Jabiri, yang berjudul Takwin Al-Aql Arabi dan bunyah Al-Aql Arabi, di sana ada Al-Jabiri ada membahas tentang irfani, burhani dan bayani. Dari kedua buku tersebut, di dalamnya sama-sama membahas mengenai tentang struktur fundamentalis kefilsafatan dalam humanities. Epistemologi dalam Islam, objek kajiannya adalah tentang Islam sebagai agama. Oleh karena itu, prior research adalah bagaimana untuk mendapatkan ilmu pengetahuan dalam agama Islam melalui epistemologi irfani, burhani dan bayani, gunanya agar keilmuan Islam dapat memberikan jawaban yang memiliki sifat humanities dan konteksnya lebih modern.

Keilmuan Islam dilahirkan berdasarkan teks yang diturunkan oleh wahyu oleh Tuhan pada masa dahulu. Dikarenakan tidak adalagi kedatangan Nabi dan Rasul di dunia ini, maka wahyupun juga telah tidak ada lagi, sementara itu semua umat Islam di dunia ini membutuhkan gerak yang bisa menyesajahterakan atas permasalahan yang masih berlangsung hingga saat ini, dan pastinya agama Islam sendiri berkewajiban memberikan jawaban-jawaban atas persoalanpersoalan manusia di dunia ini. Walaupun teksnya dinyatakan telah fix, akan tetapi ada perlunya

14 Ridhatullah Assya'bani, "Methodology of Scientific Reseacrh Programmes Imre Lakatos: Implikasi Terhadap Studi Dan Pendidikan Islam," AT-TURAS: Jurnal Studi Keislaman 7, no. 2 (31 Desember 2020): 218-31, https://doi.org/10.33650/at-turas.v7i2.1053.

15 Nurlaelah Abbas, "Al-Jabiri Dan Kritik Nalar Arab (Sebuah Reformasi Pemikiran Islam),"

Aqidah-Ta: Jurnal Ilmu Aqidah 1, no. $1 \quad$ (2 Juni 2015): 163-85, https://doi.org/10.24252/aqidahta.v1i1.1316.

${ }^{16}$ Hafizallah dan Wafa, "Pemikiran Abed Al-Jabiri Terhadap Nalar Arab."

Al-Madrasah: Jurnal Ilmiah Pendidikan Madrasah Ibtidaiyah

Vol. 6, No. 1, Januari-Maret 2022 
Ridhatullah Assya'bani : Relevansi Epistemologi dari Abid Al-Jabiri Terhadap Pembaruan Kurikulum Pendidikan Agama Islam Sekolah Dasar

dilakukan pembacaan ulang dengan menggunakan epistemologi irfani, burhani dan bayani yang sebagaimana telah ditawarkan oleh Muhammad Abid Al-Jabiri. ${ }^{17}$

Tipologi oleh Abid Al-Jabiri ini (irfani, burhani, dan bayani) sangat penting untuk dikaji karena kajian ini akan menginspirasi bayangan epistemologi Islam untuk para pemikir muslim kontemporer lainnya yang merupakan dasar untuk membangun pengetahuan keislaman. Abid AlJabiri pada awal ia merekonstruksi epistemologinya, ia mencoba dasar pemikir yang terdahulu darinya. Contohnya seperti Ibnu Manzhur, Al-Jahidz, Al-Ghazali, Al-Muhasibi, Imam Al-syafi'I, Al-Syatibi dan lain-lainnya. Asal kata bayani, Al-Jabiri mengambil dari karya oleh Ibnu Mandzur, yang isinya terdapat materi-materi Arab pada awal tadwin, yang maknanya masih murni, tidak tercampur dengan yang lain. ${ }^{18}$

Pelajaran PAI Sekolah Dasar adalah materi yang berisi agama Islam yang ada pada Negara Indonesia. PAI merupakan awal pembaruan Islam yang dimulai pada abad ke-20 dengan bertujuan untuk memadukan antara ilmu umum dan ilmu agama pada pendidikan yang bersifat nasional. Kini posisi PAI berada pada di tengah-tengah kehidupan yang bisa disebut kehidupan kontemporer. Yang mengakibatkan ada peningkatan pada keragaman dan masyarakat yang berjumlah lebih sedikit, yang mana saat ini anak-anak berkembang dalam keadaan yang berbedabeda, contohnya seperti ada yang mempunyai keluarga tiri, keluarga angkat, dan lain-lain, dan pada waktu yang sama, dengan di zaman kontemporer pada sekarang, teknologi yang semakin berkembang dapat dimanfaatkan anak-anak dan keluarga untuk menjalin hubungan sosial, komunikasi dan hal-hal yang baru.

Perubahan yang demikian dapat memengaruhi murid-murid dalam mencapai pengalaman keagamaan yang berbeda-beda. Sehingga juga dapat berpengaruh pada pengalaman keragamman pada keagamaan sebelum peserta didik memasuki ruang kelas. Keragaman ini juga ikut berpengaruh pada epistemologi yang dapat mendukung perubahan sosial. Perkembangan PAI pada saat ini tidak dapat dipungkiri bisa ada dalam perubahan tersebut, karena memang pada awalnya PAI lebih menampakkan wajah dikotomik, PAI memiliki perbedaan dengan pekajaran yang lain, terpisah dengan pelajaran-pelajaran pada umumnya, dan juga terpisah pada epistemologi. Isi pelajaran PAI yang ada di Sekolah Dasar lebih cenderung ke corak bayani dan sedikit ke arah irfani. Sedangkan pelajaran yang lain atau yang umumnya lebih mengarah ke produk Barat yang bersifat empiris dan rasional. Ini yang mengakibatkan mata pelajaran PAI tidak Al Jabiri."

${ }^{17}$ Bahri, "Bayani, Burhani Dan Irfani Trilogi Epistemologi Kegelisahan Seorang Muhammad Abid

18 Fil I. Rahmadi S, "Epistemologi Arab-Islam Muhammad Abid Al-Jabiri," TARBAWI 7, no. 01 (24 Juni 2020), http://www.journal.stitdarulhijrahmtp.ac.id/index.php/Jurnal/article/view/10.

Al-Madrasah: Jurnal Ilmiah Pendidikan Madrasah Ibtidaiyah Vol. 6, No. 1, Januari-Maret 2022 
Ridhatullah Assya’bani : Relevansi Epistemologi dari Abid Al-Jabiri Terhadap Pembaruan Kurikulum Pendidikan Agama Islam Sekolah Dasar

dapat langsung berpadu pada sistem pendidikan. Diibaratkan PAI ini berlawanan dengan sains Barat, seperti yang kita ketahui produk Barat memang berseberangan dengan pengetahuan Islam yang klasik.

Materi PAI Sekolah Dasar sering bersifat yang dogmatis, karena yang diajarkan PAI adalah produk pemikiran, bukan cara untuk melahirkan pengetahuan. Bahkan sering juga PAI Sekolah Dasar rawan terlibat radikalisme dan intoleransi, karena cara berpikir radikal bisa terbangun pada pendekatan yang dogmatis. Maka relevansi pemikiran Al-Jabiri terhadap pembaruan pendidikan agama Islam sebagai berikut, Al-Jabiri ada memikirkan epistemologi yang bisa mengembangkan multidisipliner. Sehingga sudah seharusnya PAI Sekolah Dasar dikembangkan dengan menggunakan pendekatan multidisipliner guna agar murid-murid atau peserta didik PAI Sekolah Dasar dapat menggunakan intelektualnya dengan cara pandang yang lebih luas. Sehingga melahirkan peserta didik yang pemahamannya ke arah keagamaan yang kontekstual. Epistemologi bayani, burhani dan irfani merupakan hasil dari kritik nalar Arab AlJabiri yang gunanya untuk dapat membantu mengatasi problem antara mata pelajaran PAI dengan mata pelajaran pada umumnya yang lebih kepada epistemologi Barat. ${ }^{19}$

Pada pembaruan epistemologi burhani, irfani dan bayani terhadap kurikulum PAI Sekolah Dasar, relevansi pemikiran dari Muhammad Abid Al-Jabiri ini mencoba mengembangkan dengan cara pola sirkular. Pendekatan yang dilakukan adalah dengan pendekatan tematik, yakni pendekatan yang kegiatannya dilakukan dengan cara mengintegrasikan materi pada beberapa mata pelajaran dalam satu topik atau pada satu tema pembahasan.

\section{KESIMPULAN}

Abid Al-Jabiri, nama itu menjadi nama yag sering disebut-sebut sebagai seorang intelektual Islam kontemporer yang berasal dari muslim. Nama lengkap beliau adalah Muhammad Abid Al-Jabiri. Beliau adalah orang yang sangat dihormati dan disegani oleh banyak orang dari berbagai kalangan dan banyak sekali mempengaruhi pemikiran pada generasi selanjutnya. Ia lahir pada tahun 1936 di Feji (Fekik). Ia hidup dengan berkecukupan dan terpandang. Al-Jabiri adalah tokoh yang pemikirannya sangat berpengaruh pada masa kontemporer. Namanya selalu disebutsebut dari berbagai kalangan. Ia juga seorang kritikus pada ilmu pengetahuan Arab di Barat dan di Timur.

19 Hasan Baharun dan Saudatul Alawiyah, "Pendidikan Full Day School Dalam Perspektif Epistemologi Muhammad 'Abid Al- Jabiri,” POTENSIA: Jurnal Kependidikan Islam 4, no. 1 (1 Juli 2018): 1-22, https://doi.org/10.24014/potensia.v4i1.4362.

Al-Madrasah: Jurnal Ilmiah Pendidikan Madrasah Ibtidaiyah

Vol. 6, No. 1, Januari-Maret 2022 
Ridhatullah Assya'bani : Relevansi Epistemologi dari Abid Al-Jabiri Terhadap Pembaruan Kurikulum Pendidikan Agama Islam Sekolah Dasar

Lalu pembaruannya mengenai epistemologi burhani, irfani dan bayani, terhadap kurikulum Pendidikan Agama Islam Sekolah Dasar, relevansi pemikiran dari Muhammad Abid Al-Jabiri ini mencoba mengembangkan dengan cara pola sirkular dalam kurikulum dan sistem pembalajaran Sekolah Dasar. Pendekatan yang dilakukan adalah dengan pendekatan tematik, yakni pendekatan yang kegiatannya dilakukan dengan cara mengintegrasikan materi pada beberapa mata pelajaran dalam satu topik atau pada satu tema pembahasan. Dengan demikian, pemahaman siswa terhadap materi bersifat multidimensi.

\section{DAFTAR PUSTAKA}

Abbas, Nurlaelah. "Al-Jabiri Dan Kritik Nalar Arab (Sebuah Reformasi Pemikiran Islam)." Aqidah-Ta: Jurnal Ilmu Aqidah 1, no. 1 (2 Juni 2015): 163-85. https://doi.org/10.24252/aqidahta.v1i1.1316.

Abdul Mukti Ro'uf. Kritik Nalar Arab Muhammad abid Al-Jabiri. Yogyakarta: LKiS, 2018.

Assya'bani, Ridhatullah. "Methodology of Scientific Reseacrh Programmes Imre Lakatos: Implikasi Terhadap Studi Dan Pendidikan Islam." AT-TURAS: Jurnal Studi Keislaman 7, no. 2 (31 Desember 2020): 218-31. https://doi.org/10.33650/at-turas.v7i2.1053.

Aziz, Asep A., Ajat S. Hidayatullah, Nurti Budiyanti, dan Uus Ruswandi. "Pembelajaran Pendidikan Agama Islam (Pai) Di Sekolah Dasar." Taklim: Jurnal Pendidikan Agama Islam 18, no. 2 (21 September 2020): 131-46.

Baharun, Hasan, dan Saudatul Alawiyah. "Pendidikan Full Day School Dalam Perspektif Epistemologi Muhammad "Abid Al- Jabiri." POTENSIA: Jurnal Kependidikan Islam 4, no. 1 (1 Juli 2018): 1-22. https://doi.org/10.24014/potensia.v4i1.4362.

Bahri, Samsul. "Bayani, Burhani Dan Irfani Trilogi Epistemologi Kegelisahan Seorang Muhammad Abid Al Jabiri." Jurnal Cakrawala Hukum 11, no. 1 (20 April 2017). https://ejournal.up45.ac.id/index.php/cakrawala-hukum/article/view/186.

Damanik, Nurliana. "Muhammad Abid Al-Jabiri." Al-Hikmah: Jurnal Theosofi dan Peradaban Islam 1, no. 2 (11 Juli 2019). https://doi.org/10.51900/alhikmah.v1i2.4843.

Faisol, M. "Struktur Nalar Arab-Islam Menurut Abid al-Jabiri." TSAQAFAH 6, no. 2 (30 November 2010): 335-59. https://doi.org/10.21111/tsaqafah.v6i2.124.

Hafizallah, Yandi, dan Muhammad Abdul Wafa. "Pemikiran Abed Al-Jabiri Terhadap Nalar Arab: Konsep Dan Relevansi." Mawa'izh: Jurnal Dakwah Dan Pengembangan Sosial Kemanusiaan 10, no. 1 (18 Juli 2019): 60-76. https://doi.org/10.32923/maw.v10i1.742.

Idham, Idham. "Problematika Pemanfaatan Buku Pendidikan Agama Islam Pada Sekolah Dasar Di Kabupaten Mamuju." Penamas 28, no. 2 (3 Agustus 2017): 259-76.

Musyafaah, Nur Lailatul. "Filsafat Epistemologi Islam Muhammad Abid Al Jabiri." AL AFKAR: Jurnal Kajian Keislaman XVII, no. 02 (Desember 2009): 12-21.

Rahmadi S, Fil I. "Epistemologi Arab-Islam Muhammad Abid Al-Jabiri." TARBAWI 7, no. 01 (24 Juni 2020). http://www.journal.stitdarulhijrahmtp.ac.id/index.php/Jurnal/article/view/10.

Al-Madrasah: Jurnal Ilmiah Pendidikan Madrasah Ibtidaiyah

Vol. 6, No. 1, Januari-Maret 2022 
Ridhatullah Assya'bani : Relevansi Epistemologi dari Abid Al-Jabiri Terhadap Pembaruan Kurikulum Pendidikan Agama Islam Sekolah Dasar

Ridwan, Ahmad Hasan. "Kritik Nalar Arab: Eksposisi Epistemologi Bayani, 'Irfani Dan Burhani Muhammad Abed Al-Jabiri." Afkaruna: Indonesian Interdisciplinary Journal of Islamic Studies 12, no. 2 (27 Desember 2016): 187-222. https://doi.org/10.18196/afkaruna.v12i2.2793.

Saputra, Happy. "Reaktualisasi Tradisi Menuju Transformasi Sosial: Studi Pemikiran Muhammad Abid Al-Jabiri." Substantia: Jurnal Ilmu-Ilmu Ushuluddin 18, no. 1 (11 April 2016): 1734. https://doi.org/10.22373/substantia.v18i1.3031.

Ubaidillah, M. Hasan. "Konstruksi Nalar Politik Kenegaraan Arab-Islam Perspektif al-Jabiri.” AlDaulah: Jurnal Hukum dan Perundangan Islam 2, no. 1 (2012): 68-96.

Al-Madrasah: Jurnal Ilmiah Pendidikan Madrasah Ibtidaiyah

Vol. 6, No. 1, Januari-Maret 2022 